\title{
In search of the person. Towards a real revolution
}

\author{
MICHAŁ OLEKSOWICZ \\ Wydział Teologiczny, Uniwersytet Mikołaja Kopernika, Toruń \\ oleksowicz.michal@gmail.com \\ ORCID: 0000-0001-5591-0579
}

\begin{abstract}
The discussion about a difference between brain and soul or mind is now at the center of the anthropological debate. It seems that the pioneers in this current polemic have a reductionistic view of human nature, inherited from the Cartesian solution to mind-body problem and the modern materialistic explanation of reality. This view - dualistic or monistic - about the opposition between material and immaterial structure of the person, claims that as a consequence of scientific progress, the human brain in the future could be completely explained in naturalistic terms. On the other hand, according to the new results of scientific research, this situation reveals the possibility to develop a new, more adequate paradigm of man as an incarnated person. This change was called by many researchers "the passage from the mind-body problem to the person-body problem". It seems that the Aristotelian-Thomistic approach is the most suitable to describe this "paradigm shift". Aristotelian-Thomistic philosophy undoubtedly encourages lively dialogue between philosophy and contemporary sciences through its dual ontology. Thus, it can give suitable answers for questions about the nature of human reason (intentionality); unity of composition of the human brain and the role of causality in natural processes.
\end{abstract}

Keywords: neuroscience; ontology; anthropology; intensional logic. 


\section{Introduction}

In the area of questions about humans it has always been taken into the account the important reflection about the nature of the world that surrounds us. But in modern times, that is especially after the scientific revolution, which was largely caused by Copernicus' theory and Galileo's scientific method, the attention of the natural sciences in the following centuries increasingly began to focus on the topics of man's place in the whole puzzle of the universe. It seems that the twentieth century, marked by the difficult experiences of humanity, such as totalitarianism, different wars, galloping consumerism, and economics killing the poorest, confirms that, more or less consciously, humanity was focused on the role, structure, and sense of man. In other words, the domain of questions about humanity in some way shifted from the "macro universe" to the "micro universe". How can this be justified? E.g. the tremendous progress of biotechnology, research on the DNA and on the human brain. The best-funded areas of scientific research are precisely the experiments on stem cells, human embryos, research on neurons or artificial intelligence. Thus, the rapid entry of technology into the field of human existence demands a particular philosophical reflection. What is need is a broad view of the nature of human existence. Thus, there is an urgent need to discuss the problem of the human person.

This article will present and discuss issues which were brought up in the article of Woźniak (2014). The author presents his main ideas on the basis of the research performed by M. Cortez (2010) and J. Searle (1994, 2004). He explains the theology of imago Dei in terms of rationality and the freedom of the man, which are grounded in the specific biological structures, which cannot be explained merely by biology. However, at the same time this cannot be explained by theologians as a merely spiritual dimension. On the one hand Woźniak demands rethinking traditional ideas of the imago Dei (the concept of the man being created in the image of God), the idea of the different types of causality (theological and physical) and a broader articulation of the material character of nature. But on the other hand Woźniak claims that there is need of a new approach that will be able to mediate between the 
ontological monism and dualism which means, according to him, can be called "the moderate monism" (Woźniak 2014, 280). This article will be an attempt to show how thanks to the combination of Aristotelian-Thomistic philosophy with new scientific results, we can rethink the concept of matter and the human corporeal being with a dual approach.

\section{The limits and shift of paradigm: from the mind-body to the person-body problem}

In the twenty-first century the idea of the scientific progress is most probably not shocking for us. In the modern era, when the results of mathematical-empirical method were really spectacular, it was normal to assume that the absoluteness of scientific results. But already in philosophical field, Kant's thesis were broadly questioned by Hegelian metaphysics and a strong arguments against the pure formality of human cognition were put forth by F. Brentano and E. Husserl. Hegel proposed the tenant that historical conditions determine human existence. This idea was later reinterpreted in merely scientific view by the positivistic movement. But F. Brentano and E. Husserl work caused the renewal of the discussion about human intentionality. Since the Galilean times, as explained A. Koyré (1980; $160,163,167)$, modern science was strongly connected with neo-Platonic metaphysics. It claimed that the distinction between metaphysics and science has not been properly demarcated. Thus, modern science made the passage from the cognitio certa per causas to the cognitio certa per leggis (Maritain 1974, 44-45) that in Newton's research meant to attribute the apodictic character of cognition through physical laws (Newton 1704, 326). But in the near future, the physics of the Newtonian-Laplace model was questioned by a series of physical discoveries: statistical thermodynamics of Boltzmann; inherent instability of the dynamic systems with more than two bodies (demonstrated in the work of H. Poincaré); the quantum physics (W. Heisenberg); the relativistic physics (A. Einstein) and nonlinear dynamics and thermodynamics of the so-called complex physical systems (Basti 1991, 35-43). 


\subsection{Antinomies, axiomatization of the philosophical logic and intentional paradigm}

The separation between the cognition through causes, essences (according to antic philosophy of nature) and the apodictic-mathematical method prepared the conceptual background for the future axiomatization of mathematics (mathematics as the formal theory distinguished from interpretations - different models). On the one hand, the birth of non-Euclidean geometries clearly demonstrated that the mathematical theories and its interpretations "incarnated" in the physical theories have a hypothetical character. But on the other hand, axiomatization, which began with the discovery of Riemann and ended with failure of Hilbert's program, revealed, thanks to works of G. Cantor and Russell, the syntactical (and not only semantic) character of logic antinomies explained in K. Gödel's incompleteness theorems of arithmetic. In other words, the antinomies discovered in the fundaments of the mathematics had the metaphysical character. The hidden sense of this antinomy consisted in the lack of adequate distinction between the notions of "essence" (a set of properties and relationships that determine a subject) and "being" (existence of the subject which is a fundament of metaphysical properties and relations). From linguistic point of view, this implies the insufficiency of the "expressive power" of the univocal language and calls for the need of the theory of analogy, since ordinary languages have unavoidable semantic dimensions and ordinary experiences are intrinsically intentional (Basti 2007, 193-201).

The typical for above mentioned functionalist approach is the Kantian interpretation of the cognitive act in the terms of representative character. In this view, human cognition stabilizes the functional correspondence between things external to the brain (the state of objects) and the mental state that was caused by activation of the neural circuits. According to Fodor's work (1980) the dispositional states activated in the neural networks form the propositional attitudes, symbols of the language of thought. Even then J. Fodor $(2001,2008)$ was trying to avoid the representative consequences of his approach, although in fact, in the functionalist approach based on 
the extensional logic the brain exhibits only a passive work in order to stabilize the equation between the internal and external state. Thus, the task for biological and cultural evolution is to stabilize the basic symbols and categories between externally perceived human reality and human thought. Although Fodor's contribute is essential to the birth of cognitive science, the inevitable epistemological limit of this discipline is contained to the use of extensional logic. A functionalist approach is not sufficient for the explanation of the intentional character of the human cognition and the different types of human reasoning that are not only computing data but also inventing (Basti 2009, 191-194).

This shift of the paradigm in logic is linked to the aforementioned idea of axiomatization, not only in the mathematics but also in logic. Thanks to the work Principia mathematica (1910-1913) of A.N. Whitehead and B. Russell, the idea of axiomatization of mathematical logic (extensional logic) could be realized. But the application of this type of logic to the whole of human culture, according to the Wittgenstein's Tractatus Logico-Philosophicus and its diffusion by neopositivism movement and analytic philosophy, caused the reduction of the scope of philosophical language. Because extensional logics (first of all mathematical logic) are based on the so-called axiom of extensionality: "Given any set A and any set B, if A is a nonempty set (that is, if there exists a member $\mathrm{X}$ of $\mathrm{A}$ ), then if $\mathrm{A}$ and $\mathrm{B}$ have precisely the same members, then they are equal". From this logic we find a ground for the empiricist dogma, that the mental and physical states are equivalent (isomorphic). But already in 1912 the American logician C.I. Lewis (1912) revealed the limits of the concept of logic included in Principia and explained philosophical logic using the idea of axiomatization rather than reducing it to mathematics. But in reality, his Symbolic Logic published in 1932 can be considered as the first text of modal logic axiomatization. As with works of Frege, Whitehead, Russell began the axiomatization of extensional logic (that prescind different semantics). It was C.I. Lewis who started the shift and the beginning of very important work on axiomatization of intensional logic (ontic, deontic, epistemic). This logic differs from the previous one firstly due to the use of diverse semantic interpretations (senses) of notion of necessity 
and secondly because of the sense given to the notion of the predication (different criteria of the truth that depends necessarily from the truth and false of proposition's components) (Basti 2012, 31-47). In the light of this logical works, but also thanks to the contribution of neopositivistic formal analysis of intensional statements, the theory of identity (so-called empiricst dogma and dogma of $A I$ ) was disproved in its strong version. The intentional statements are used by the subject to express own conscious mental states (I-talk) and they have the form always referred to some content (e.g. I like/ want/see/think something). They are distinguished from the statements of the outside observer (O-talk) in which are expressed the statements of neurophysiological description of mental states. The first one are expressed in the intensional logic, the second one are necessary expressed in the extensional logic and both are mutually irreducible (Basti 2009, 203-210). J. Searle made a further critique of the functionalist approach and its use of mathematical logic questioning it as the unique synonym of rationality. He stressed that the intentional character of human cognition implies use of intensional logic although he did not choose this approach for his future researches (Searle 1980; 1983; 2007). To conclude, the mind-body problem is before the ontological, it is situated on the logical level (irreducibility of I-talk and $\mathrm{O}$-talk). The ontological and logical component of the discussed problem call for a consistent theory of information and application of these notions and measurements in cognitive and biological systems (Basti 2005, 172; paragraph 1.2.).

There are strong links between the representative approach in epistemology, the cognitive sciences and anthropological monism. In the case of materialistic monism, the mind is reduced to the collection of the mental states produced inside some of the parts of the body - specifically in the brain. As Basti (2009) rightly observes, through the modern contributions of Descartes, Hume, Kant and Frege's logic, the extensional interpretation of logic and the supposition of the identity between physical and mental state of mind dominated the discourse about mind-body problem. But in recent years there can be seen a shift from the representative/functionalist approach based on the extensional logic to the intentional approach based 
on the intensional logic. The technological progress, called "research for the third informatics revolution" (Web 3.0), consists in use of logical calculus based on the principles of modal and intensional logics. The Web 3.0 could be called "the intelligent Web" because the coming third generation of Internet-based services, which emphasize machine-facilitated understanding of information, appeal to the intuitions and experiences of the human users. In this context, intensional logic is not only non-extensional but also as the logic of discovery (inductive and not only deductive). Thanks to the recovery of intensional logics it is possible to make progress in simulating human behavior in what the research of new generation of robots is called formal ontology engineering. In other words, in actual technology, through use of formal ontology, the role of human intentionality is recuperated. In the context of a representative approach, extensional logic (but also the intensional logic that does not analyze human actions) cannot exceed the semantic and syntactic analysis and cannot expand its research domain over human language or the state of human consciousness. From the formal point of view, the classic problem of reference remains unsolvable from within this approach. However, the problem of extralinguistic reference is solvable within the causal theory of reference (Donnellan 1966; Putnam 1975). This theory is linked with the turning point in H. Putnam's scientific research (Putnam 1960) - the shift from functionalist theory to intentionality (Putnam 1988) - and is linked to the works of Kaplan (1978) and Kripke (1980). The reason for this shift is that the representative paradigm does not provide any possibility to establish cognitive realism. The intentional paradigm prioritizes human action preeminence over the representation. This passage (thanks to the formal ontology that takes account simultaneously of all three classes of relations - pragmatics, syntax, semantics) means that the representative moment (syntactic-semantic) of human cognition is the function of intentional moment (pragmatic) where the representation depends on the causal action to/from the subject from/to the cognized real object (Basti 2007, 204-208; 2009, 206-210; 2015, 115-120; Salmon 2005; Cocchiarella 2007). 
Basti $(2009,194)$ explains that typical for the intentional approach is to have as a paradigm not the sense of sight (Platonic view) but the sense of touch (Aristotelian view). Through touch one is acquainted with the consequence of human action. The motor action of body, as the reorganization of internal dispositions, constitutes the real cognitive moment in complex intentional act. In the Aristotelian approach this act is not interpreted as static internal representation of external conditions but means continuous, active and adaptive self-modification (imminent action) of dispositional states of the brain (habit) from/to the environment in the reciprocal control, with dispositional states of whole organism, in view of the actual achievement of the purposes. Thus the intentional act is not the act only of the brain or mind but is executed by the whole body, by the person. The truth is not considered as the static representative equality (aequatio) but as the dynamical, continuous adequacy (ad-aequatio) of our dispositions to action (cognitive habits). It means that our mind or brain not only calculates on the basis of a priori symbols (sets, classes and its functional relations) but is constituting and progressively making adequacy between the logical symbols and the objects at which those symbols are referred and redefined in the base of the relation with the subject's aims. In other words describes this particular character of logic of our minds W. Freeman (2001, 120-121):

This description, whether he [Merleau-Ponty] intended it to or not, clearly conforms to Aquinas's process of assimilation, by which the brain learns about an object by making itself similar in selected aspects to the object through organization of the body and neuron throughout the brain. He appears to make a distinction between the horizon of the world outside and the horizon of perception within. [...] The act of perception transcends the two horizons through assimilation. Our perception of an object has already been conceived before the sensory input, by the action taken to obtain the input. The structuring is done by repeated cycles of action and perception that Merleau-Ponty calls the intentional arc, which constitutes the effort to achieve maximum grip. His putting each detail within the perceptual horizon essentially means positioning the sensory receptors through efference and focusing the sensory cortices through preafference, which is to pay attention in order to achieve optimal 
assimilation of the self to an object. The self adapts to that object and learns about by shaping the body, and also by reshaping or repositioning the object. A familiar example is manipulating a new tool with our fingers, squeezing it, inspecting its facets visually, listening to the sound it makes when it is tapped, and then applying it to other objects as we conceive and configure them.

To sum up, the logic of our minds is not the logic of merely calculation but of continuous adaptation. The shift from the representative-static paradigm to the intentional-dynamic was ultimately decreed by the series of cognitive and neurophysiological evidences accumulated in the last years (Basti 2009, 195-197; Basti 2014, 226-231):

1. The collection of many years' explorations expressed in the work of A. Damasio (1994) showed the neurophysiological importance of the human emotions. He proved that patients with defects in the emotional area of the brain were unable to make decisions favorable for themselves and acceptable by the social environment. The work of Damasio revealed the error of Cartesian res cogitans (and of Kant) to separate the ethics from the emotional sphere. In this recent work (2010) he discussed the distinction between the consciousness, self-consciousness and observable behavior. In this view the author developed the idea that the mind should not be understood like the Cartesian vision of the mind in the body, but on the contrary, working as a controller over the body which the mind "contains". Damasio's works can be considered as opening the discussion about the intentional interpretation in the cognitive neuroscience.

2. In the neural network there does not exist a separation between the learning and recognition phase. The neural network is in continuous learning/recognition phase.

3. Activation of the neural circuits during the same behavior effects the activation of the same brain area but always with different neural circuits activated. Thus, in cognition and neurological circuiting, the same input give different responses/replies.

4. The single neurons codify over time the different input over time, as evidenced by the contribution of Hubel and Wiesel research on the 
simple and complex cells and on the development of the visual system, which involved a description of the ocular dominance columns.

5. In the functionalist approach, it was hypothesized that there is rigid functional distinction between the sensory, association and motor cortex. But the discovery of the mirror neurons and studies based on them (Rizzolatti \& Sinigaglia 2006) demonstrated the omnipresence of the motor neurons that codify not single movements but coordinated movements.

6. On the basis of the instability (point 2) and non-stationarity (point 3) of brain dynamics, it can be concluded that its physical character can be described in the terms of chaos theory. This was the conclusion of the Freeman's group (paragraph 1.3). This would mean that brain memorization is dynamic. Memorization means reactivate the complex dynamic between the system of neurons of the limbic sub-cortex area and a network of neurons from the sensorimotor cortex. These last neurons are always different but they are activated to reproduce the same global effect of intentional assimilation which is on the base of that memory.

\subsection{Towards the theory of information}

In order to understand the discovery of Freeman's group it is necessary to explicate fundaments of the informational interpretation of the quantum physics in its two versions: quantum mechanics (QM) and quantum field theory (QFT). This interpretation is closely related to the research on the issue of the information performed by Basti (2012, 47-71). Basti gives the intuitive definition of information as the relation of the order of the parts that could have been ordered in another way. As it will be demonstrated after, this definition corresponds to Aristotelian notion of the form. But this preliminary definition can also be understood in correspondence to the scientific notion of information - in mathematics related to the notion of improbability (in mathematical physics this notion is linked to the statistical notion of the entropy) and in logics related to the notion 
of the undecidability. The application of the notion of the information in the field of physics, mathematics and logic justify the use of its another definition: "the physical measurable but immaterial quantity" (Wheeler 1990, 75). In modern times our philosophical intuition has been influenced by the dualistic view of reality. This means that the notion of form or formal cause are often interpreted as some kind of immaterial efficient cause. The dualistic and Cartesian vision strongly influenced the researches about the mind-body problem where the explanation of the action of the soul often meant the competition between the biological forces of the body and the possible impact of the soul on the body. On the one hand, the reduction of the physical causality only to the causal action and, on the other hand, totally misunderstanding the real significance of formal cause, resulted in the absurdity of many philosophical discussions. Otherwise, these definitions of information can be metaphysically explained in the dual ontology through the notion of the form (act, determination) and the matter (potency, indetermination). In the Aristotelian view, the form depends on the causal foundation that comes from the action of an efficient cause on the undetermined substrate. The different order of efficient causes can determine totally different effects. In other words, to product some effect, the set of efficient and material causes is not sufficient, as there is also the necessity of its order, its form.

The first who introduced the idea that physical entities are ultimately constituted from the energy and information was J.A. Wheeler (1992). The idea of the information as the physical quantity has been in recent years broadly discussed in the camp of fundamental physics. In this camp two main ontologies dominate the notion of information: naturalistic and conceptual. The second is defined by Basti (2016, 5-6) as an intellectual exercise, but the first one provides the ontic notion of information. This means that within naturalistic ontology, the information is considered as the physical quantity, distinct from the matter (mass-energy) in which it is placed. The most important results from this approach can be summed up in the works of P. Davies (2010), P. Benioff and G. Smoot. Firstly, the ontic definition of the information questions the strong connection of modern science 
with the neo-Platonic metaphysics of logical realism. In the naturalistic approach the mathematical laws of physics and their evolution are based on the evolution of the universe, because there is mutual determination between the mathematical laws and the physical processes. The principle of this approach is named computational coarse graining (Perrone 1995; Basti \& Perrone \& et al. 1995; 1996). Secondly, the studies on entropy and on the inflation of the universe revealed that the gravitational force can be interpreted as the entropic force that generates information. The works of S. Hawking and J. Bekenstein showed the possible measurement of entropy that can be associated to a black hole (Hawking radiation). Through the works of G. 'tHooft and L. Susskind this idea was applied to the string theory of physics and to the event horizon enclosing the expanding universe, defined as the principle of the holographic universe. The increase of the physical confirmations about the strict correlation between gravitation, thermodynamics and information allow us to say that the past states of the universe contain causally, but not logically, the future states of its evolution. Hence a mechanism of actual information growth is required because the growth of the information is connected with the area of the event horizon containing the universe. This interpretation can be called as "the causal origin" of the information in the key of the naturalistic ontology (Basti 2016, 7-8). This mechanism does not mean that the quantity of the information is already written in the cosmological horizon. Rather it is written in the causal factors which are able to generate it. These ideas find the correlative explanations in the Aristotelian's concept of educing the form from the matter (section 3) and in the Aristotelian theory of the natural place. This last idea was based on the Aristotelian thermodynamic concept of physics where the spread of heat upwards signs the anisotropic character of the physical space. As a consequence, the Aristotelian celestial spheres built from the special element (aether) and the eternal and unchanging bodies (lightest and more ordinated), are said to be the cause of the terrestrial, irregular events. It can be claimed that the celestial spheres had the same ontological function as the event horizon of the holographic cosmology. Thirdly, this cosmological interpretation of the information has its continuation in the biology research 
based on the informational approach. This approach is linked to epigenetics and to the anthropological vision which is capable of recovering the dual approach in the anthropology and the notion of the psychophysical unity of the person (Basti 2014, 240-247). From the 1960's when modern genetics, based on the already mentioned progress of the program of AI, was developing the inquiry of the human DNA, the idea of the Aristotelian form has found its own place in biology and psychology and was interpreted under the notion of information incorporated in the brain's or organism's interchange of matter-energy. The grate "skip" in the biological field has happened in recent years and is linked with the progress of the epigenetics. This study, in the field of genetics and phenotypic trait variations, clearly shows that variations are caused by external or environmental factors (biochemical signals) that ordinate the changes in gene expression in absolutely individual way. Hence, as it was conceived by the founder of the epigenetics C.H. Waddington, the embryonic development depends not only on the genome but also on the epigenetics. On the other hand, the dual approach in biology strictly depends on the physical foundation expressed in the language of QFT.

\subsection{Quantum field theory and chaotic systems - towards the dissipative QFT approach}

The starting point of the QFT approach is the evidence that for every physical reality underlies a field of irreducible forces - the vacuum state. This constitutes the common substratum of each physical reality and has its corresponding notion in Aristotelian the raw material - the indeterminate matter. QFT provides the opportunity to understand the missing link in the biochemical processes. As Basti underlines (2014, 240-250) the vital functions, at its fundamental level, are the ordinated and coherent sequence of the chemical reactions. But these reactions do not depend only on the chemical factors working well in short distances but also depend on the factors that are organizing its movement, especially in the long distances. This theory shows the explanation that the efficient way to organize the casual processes of the molecules consists in putting their characteristic 
oscillation, which depend on the quantum laws, under the influence of the electromagnetic fields that are oscillating with the similar frequencies. This means that in the heart of biological interpretation of QFT we find the thesis that each biological function is constituted by the ordinated frequency of chemical reactions. This dynamical principle of the control of the reactions (fine tuning) means that the electromagnetic field which is in resonance with the appropriate frequency of the biomolecules, closes them and the chemical reaction could be done. In this light it can be said that QFT may in the future provide more accurate and mathematically defined explanation of emergence processes, more adequate than the proofs offered by Popper's (1977) and M. Bunge's ideas (1980). In QFT, the emergence of the macroscopic characteristic (the structure and the functions) is given through the dynamic process which determinates the arrangement of the system. Hence the quantum properties (the quantum entanglement, non-locality, discretization of space and time, the dual nature - energy and information - of every physical process) are not only limited to the microscopic level but there is clear macroscopic evidence in, e.g. the ferrous materials, the laser, the superconductivity of some materials, the self-organization of the organic molecules in vital and cognitive processes. In brief, the emergency properties depend on the way in which the oscillations of the fields associated to the component molecules are organized. Thus the dynamical process is the process of the increase of information because the dynamical correlation means the symmetry breaking and the emergence property are really new properties not reducible to the properties of the fundamental components or to the sum of them. In the QFT, the correlation between the force fields is propagated by the Goldstone bosons (the quantum of correlation). In the difference to other bosons (gluons, photons, $\mathrm{W}^{+-}, \mathrm{Z}$ and Higgs boson) they are not mediators of energy (matter) but mediators of modality of the interactions between different force fields. In other words, they are not the quantum of the energy but the quantum of the correlation/information. Hence, on the basis of the Goldstone's theorem, when the ordinated state of objects loses its property, by virtue of the first law of thermodynamics, the energy and correspond- 
ing quantum are preserved, but the ordinated state and corresponding Goldstone bosons disappear. The Goldstone bosons do not exist outside of the systems which they organize (e.g. the magnons in the magnets, the phonons in the fluids and crystals and DWQ in the living matter). Hence it can be said that they are the physical manifestation of the metaphysical form of the entity. In this context it is clear that the Aristotelian notion of the form has nothing to do with the idea of "obscure", invisible form that competes with material and efficient forces. As suggested J.A. Wheeler the forms are organizing different matters and they have its corresponding, operational modality - the physical measurable but immaterial quantity: the information.

G. Basti and A. Perrone have in many of their works (Basti \& Perrone 1995 ; 2001; 2002; Basti 2009) emphasized that the physical basis of intentionality can be explained only in the terms of the long-range correlations that are propagated in real-time along the wide cerebral areas and which manifest themselves as the aperiodic chaotic oscillations. This means that a valid dynamical explanation for an intentional act (which always involves the simultaneous interaction between emotional, sensory and motor components of the distant cerebral parts) can be provided. On the other hand, the crux of the criticism of G. Basti $(2008,166-171)$ directed against C.H. Waddington consists in a critique of Waddington's attempt to explain epigenetics mechanisms through the catastrophe theory originated with the works of R. Thom and V.I. Arnold. But this theory is absolutely insufficient to justify the complexity of the epigenetics dynamics of the livings, because the nonlinear systems studied by Arnold are characterized by the structural stability. But in reality, the living beings are the dissipative structures which stability is far from equilibrium. The discovery of these systems - called the chaotic systems (see below) - described by I. Prigogine is the key for the study of the physical basis of human intentionality in the cerebral dynamics. From the study of the chaotic systems and as well as from the study of QFT new areas of research opened up. Hence more than forty years of experimental research of W.J. Freeman from the University of California at Berkeley and his collaborators not only shared the same 
theoretical convictions of Basti and Perrone but observed and measured this type of dynamic phenomena in mammalian and the human brains during the intentional act. The collected data of Freeman's group found its proper representation in the physical-mathematical modeling in the dissipative QFT approach of G. Vitiello and his collaborators (Freeman \& Vitiello 2006; 2008). In brief, Freeman and his group used different techniques of brain imaging (EEG, ECoG, MEG) to study the background activity of the brain which is often filtered by neurophysiologists as a "noise" with respect to the synaptic activity of neurons.

By studying these data with computational tools of signal analysis to which physicists, differently from neurophysiologists, are acquainted, they discovered the massive presence of patterns of AM/FM phase-locked oscillations. They are intermittently present in resting and/or awake subjects, as well as in the same subject actively engaged in cognitive tasks requiring interaction with the environment. In this way, we can describe them as features of the background activity of brains, modulated in amplitude and/or in frequency by the "active engagement" of a brain with its surround. These "wave packets" extend over coherence domains covering much of the hemisphere in rabbits and cats (Freeman W. J., 2004a; 2004b; 2005; 2006), and regions of linear size of about $19 \mathrm{~cm}$ in human cortex (Freeman, Burke, Holmes \& Vanhatalo, 2003), with near zero phase-dispersion (Freeman, Ga'al \& Jornten, 2003). Synchronized oscillations of large scale neuron arrays in the $\beta$ and $\gamma$ ranges are observed by MEG imaging in the resting state and in the motor-task related states of the human brain (Freeman \& Rogers, 2003). (Basti 2016, 30)

To sum up, as explained Basti, the "wave packets" extended over the coherence domains covering much of the hemisphere of observed living beings form a kind of "harmonious orchestra". As a consequence, the intentional recognition of the input/stimulus corresponds to the establishing the coherence domain ("the melody") in the cerebral area while the phase delay establishes the aperiodic chaotic regime ("the cacophony", stochastic chaos). Thus, the nature of the correlations among the elementary components in living matter is based on the phase correlations 
which is the result of the role of Goldstone bosons in the fine tuning of the elementary oscillations. This means that only some of the infinite modalities of the oscillations remain in order to being in phase, to create the order and so the information (Basti 2016, 25-26). But the most significant, spectacular consequences coming from the experimental research of Freeman and his collaborators are: 1. The transfer of information from the environment to the brain is not only a passive process, since the brain while is responding to the stimulus, is already generating the information. It shows that the intentional model of cognitive action is more adequate than the representative model. Cognition means the active process, the process of the continuous adequacy (ad-aequatio) of our dispositions to action. As a consequence of the same stimulus, different brains will give the different responds because they have different stories. 2. All these considerations have the independent evidence in the physic-mathematical model of QFT dissipative. In this approach the brain is considered as an "open”, "dissipative” system continuously interacting with the environment to give to this system a potentially infinite capacity of memory. From this model emerges the need for the doubling of the degrees of freedom principle that represent the environment to which the brain is coupled. "The environment (state) is thus represented as the time-reversed double of the brain (state) on which it is impinging. The environment is thus modeled on the brain, according to the finite set of degrees of freedom the environment itself elicited. Anyway, which are the available degrees of freedom to be elicited for that input depends on the brain itself that, for this reason, is effectively a self-organizing system" (Basti 2016, 31). All this mean that what continuously changes in the brain is not energy (matter) but the information. The input produces in the cerebral dynamic not the global variation of energy but the coherent domain ("the melody", the information). This "melody", the coherence domain which is propagated in the complex cerebral dynamics ("the cacophony"), is not only "in the head" but is located in the dynamical interface between the brain and the environment. As the consequence the mind is not in the head but it contains the brain and the whole body (Basti 2014, 243-246). 
As has already been mentioned many times one of the main causes of the birth of new paradigm, is called in the scientific literature of physics the complexity theory. From the discovery of inherent instability of dynamic systems in the work of H. Poincaré to the further studies on behavior and condition of the dynamical systems brought the unexpected results. The most important for discussed topic the features of these systems are (Basti 2002, 142-174):

1. The studies of chaotic systems, that gave a rise to the complexity theory, can use its descriptive models to explain and unify the levels that were previously separated - the microscopic level (quantum mechanics), the mesoscopic level (thermodynamics), macroscopic level (classical mechanics), the megaloscopic level (general relativity). Examples of chaotic systems are presented on all these levels.

2. Although there does not exist a mathematical theory that explains in a satisfactory way the chaotic systems, there is the possibility to provide approximate mathematical theories. What can be certainly said is that chaotic systems are not congruous with the stochastic systems. It means that generally with the notion "chaotic system" or "deterministic chaos" one is describing the physical deterministic process in which the final state depends causally on the initial state. But the nonlinear irreducibly nature of the equations of system affects the exponential divergence of trajectories what gives the inherent unpredictability of the system's behavior in long period of time. In other words, from the acquaintance of the initial conditions it is not possible to predict with certainty the final state.

3. The study of the dynamical instable systems and chaotic systems gives the opportunity to comprehend the dynamical basis of the dissipative structures (the Nobel Prize for I. Prigogine in 1977). These structures are essential to understand the physical basis of self-organization and self-adjustment typical for the chemical and biological systems. Without this research, the scientific explanation of richness and diversity of life or reflection on the phenomenon of freedom would not make any sense. Complex systems are giving the 
objective, realistic foundation for the physical processes that are contingent and not determined in the way suggested by the Hume's, Kant's, and Newton's deterministic intuitions. The KAM theorem showed (against the enthusiasm of Kant and Laplace) that the dynamical systems are generally not integrable and do not obey the ergodic hypothesis. But on the other hand, they include other ordinated structures named chaotic attractors (strange attractors). It means that the dissipative structures can generate the information because the structure of the chaotic attractor in the chaotic behavior dissipates the information of initial conditions in the process of divergency and generates the new information thanks to the mechanism of folding the divergent trajectories. Through this dynamical mechanism the new, totally unpredictable on the basis of the initial conditions structures come to existence thanks to the deterministic character of laws that governs this process. This emergence of new order from the chaotic structure shows the strong correlation between the chaotic systems and the emergence of dissipative structures in nonlinear thermodynamics systems. Thus the new order not results from the initial conditions but from the global causality - the global factors that control the whole dynamic and can be known only after occurrence of the final state. In this context the Aristotelian model of causality, based on the notions of act and potency and four causes' description, can be considered as more adequate to describe the causal relations in the ontology of chaotic systems.

To conclude in this part, the study of the logic of our minds reveals that it is not the logic of merely calculation but of the continuous adaptation. But, as it was mentioned, the shift from the representative-static paradigm to the intentional-dynamic was ultimately decreed by a series of cognitive and neurophysiological evidence accumulated during the last years. Especially, chaos theory can use its descriptive models to explain and unify the levels of reality that were previously separated - the microscopic level (QM), the mesoscopic level (thermodynamics), macroscopic level (classical mechanics), the megaloscopic level (general relativity). The QFT can offer 
the link between the microscopic and macroscopic phenomena and provides a rigorous approach to the otherwise ambiguous notion of the emergence of ordered structures at mesoscopic/macroscopic level.

\section{New paradigm: dual ontology}

The objectification of the human soul/ "I" (res cogitans) led to a discussion of the problem in two ways: the negation of particular character of the human "I" (Ryle 1951), or on the other side, the attempt to justify the " $I$ " through the analysis of self-consciousness (via the subjective which started with the thought of Saint Augustine and became widespread in modern philosophy). Likewise, the abandoning of the mechanistic view in contemporary biology and physics lead to the renovation of a dual ontology of reality - reality that is composed of two physical quantities: information and energy-matter. The spirit is then not something (brain, mind; res cogitans) inside the other thing (body, the set of physiological and neurophysiological functions; res extensa) but is the living body, the person (Basti 2014, 224-226). The self-evidence of consciousness, as clearly demonstrated by Thomas Aquinas (De Veritate X, 8; XXII, 12), is not enough to found the substantial, spiritual and rational nature of the human soul. Self-consciousness can only give us evidence of the psychical dimension, but is incapable of revealing the real nature of the psychical dimension (Basti 1991, 103-119). Moreover, as in Descartes' and Popper's theories, each dualistic view in which the soul has to displace particles would violate the first law of thermodynamics. This means that if the soul was the Cartesian res cogitans, the only possible approach would have to be a materialistic one. This assertion is a substantial misunderstanding that is the fundament of contemporary discussion about the mind-body problem. The common characteristic of these ideas is the critique of Descartes' dualism and the identification of the mind with something separate from the body. But many cognitive philosophers have moved from the representative paradigm (mind-body) to the intentional paradigm (person-body) (Basti 2012-2; Basti 2014, 233-234; Clark 2013). 


\subsection{Against extensional reduction of the predicate being}

How can it be possible to link the informational approach to Aristotelian ontology (Basti 2005, 173-174)? The first attempt can be found in the idea proposed by R. Penrose (1994, 13):

Most of the material of our bodies and brains, after all, is being continuously replaced, and it is just its pattern that persists. Moreover, matter itself seems to have merely a transient existence since it can be converted form one form into another. [...] Thus, matter itself is nebulous and transient; and it is not at all unreasonable to suppose that the persistence of "self" might be have more to do with the preservation of patterns than of actual material particles.

The fact that our bodies are physically changed almost two times a year combined with the factual continuity of our " $I$ " means that our consciousness is not depending on the matter but rather upon some pattern - the information - that organizes matter. Moreover as in the dual ontology, form and always matter goes together, meaning that the informational flow always has to be incorporated into the energetic flow. And finally the broadly discussed problem of the localization of mind respectively to the body finds in the informational approach another solution - the mind includes the body. The mind is located in the informational flow of the control between the body's organs and between the body and the environment. In other words, the flow of control contains the physical systems, hence is governing the body (McKay 1980, 1390). The same idea is expressed by Aristotle (De Anima, I, 411b) and Thomas Aquinas (Summa Theologiae, I, 52, 1c; 76, 8c) that the localization of the soul is explained in the terms of the extension of its power of control over the body. Consequently, the soul contains the body, not the other way around.

This is not the place to discuss the whole issue of the Aristotelian metaphysics, but it is important to consider the aspects contained in the scientific discipline which uses the formal methods of symbolic logic and the philosophical analysis - the formal ontology (Basti 2007; 2015, 80-86). Fundamental for it, as previously mentioned, is the distinction between 
essence and existence. The being of the essence concept ( literally means "the what it was to be" or "the what it is" and corresponds to the scholastic terms quiddity and haecceity. The being of the existence (common being) expresses the fact that the individual substance really exists. Through this distinction, medieval ontology was able to express the identity (the identity of the essence, quiddity) without equivalence (the identity of the relation between the part and the whole). But modern logic is based on the set theory and on the axiom of extensionality, reducing the predicate being to the syntactically correct use. This means to affirm in a consistent manner that the examined element belongs to the examined set. This ontological distinction implies immediately a critique of the monistic approach and its semantics and anthropology. The previously discussed distinction between intentional statements (I-talk) and observation ones (O-talk) showed that both are logically irreducible. This is exemplified in the famous example of Quine $(1987,163)$ who explained that the enunciate "I think Vienna" is not translatable into the observation enunciate of the determined cerebral processes correlated to the verbal act and to the relative mental state. This means that there are two different and irreducible logical connotations of the same denoted entity ("Vienna" in the example of Quine). Basti (2005, 177-178) suggests an another axiom of this ontology. Beside the distinction being of essence and being of existence it can be said that the entity (quiddity) of the denoted existing - the neurophysiological event - has a twofold and irreducible component: material and formal. This is both at the level of intentional language and its intensional logic and at the level of extensional language and its extensional logic. Thus, the neurophysiological event is not only matter but matter organized by the form, as we find in the Aristotelian ontology. In other words, the intentional statement (I-talk) has its intensional ("what I mean") and extensional content ("towards what I am referring to"). But also the intensional content (noema) has its material and formal component. In Husserl's phenomenology, noesis designates respectively the real content, and noema the ideal content of an intentional act (an act of consciousness). Noesis is always correlated with a noema. Because the noema also has its 
twofold component the noematic sense is generally understood as the ideal meaning of the act and the noematic core as the act's referent or object as it is meant in the act. But really important for this discussion about the noema's component is the question if the noematic distinction between form and matter of the perception, has the real, objective fundament at the level of denoted existing. It can be claimed that the phenomenological distinction of the cognitive contents and the linguistic statements has the realistic basis.

This formal basis is the core of the Aristotelian ontology and means that each existing thing, connoted through the dual description (subjective-intentional and objective-scientific) is the entity compound from matter and form. But in Aristotelian view, matter and form do not imply separated entities. As the scholastic philosophy explained, they are not ens quod but ens quo. They are not id quod existit (the thing that exists) but they are id quo aliquid existit (the medium by which something exists). In other words, matter and form which connote the existing object are not referred to the objects (or to its parts) but the relations constituting the object, that is to say, the essence of the considered existing entity. In brief, the Aristotelian ontology gives a causal explanation of essences through which the entities are actually existing. In other words, for Aristotle, because the matter and the form are id quo aliquid existit, each form is educed (comes out) from the potentiality of the matter. The form is not added from the outside of matter but because of the moving cause, arises out of matter. But educe the form from the matter is not the same as logically deducing the theorem from the premises. Aristotle in a dynamic way justifies the diversity and multiplicity of the entities. He uses the idea of the raw material which indicates the potency to take the infinite material forms. In brief, for him matter is in incessant movement - it is undetermined. But the forms are not hidden in the matter but there are potentially existing in it until the moving cause will be able to determine the unstable movements of the elements in the matter. Thus educe means to put the limit to the becoming of matter. It means to stabilize the chaotic movements according to the ordinated configuration named the disposition. For Aristotle the form (act) is always related to the 
potency (matter), derived from the efficient, external cause and is the end, the determination of the incessant movement of the matter. It can be said that there is a structural similarity between Aristotelian physics and modern physics. The Aristotelian distinction between the celestial and terrestrial physics can be transferred into "the heart of the matter" studied by the quantum physics, as the physical and chemical properties of the chemical elements depends upon the atom's wave configurations of electron's motions. The atoms of the same element demonstrate a fundamental identity of species - the electronic wave subjects the same structural limitations as the atomic nucleus (Basti 2002, 343-354).

This study of the matter and the form is the core of Aristotle's strong critique against all types of the monistic and materialistic philosophies. Not because he believed that there should be some kind of "magic force" (the form) which would work behind the scene, but because he based his physics on the physical, especially thermodynamic approach. The Aristotelian idea of the matter cannot be reduced to the modern idea of the Newtonian mass, but rather must be understood in terms of the incessant movement of the elements. For Stagirite, the particles that constitute matter have forces - the dispositions, that in his view of physics can be translated into thermodynamic heat. This means that the Aristotelian thermodynamic interpretation of the physics strengthened his conviction about the irreversibility of many physical processes. The essential presence of heat in natural processes means that they do not entail modifiable directions of evolution - they tend towards a new structural stability. Thus this point is the fundament of Aristotelian teleology. As it was mentioned earlier (paragraph 1.2.) the Aristotelian physical space is characterized by the anisotropic character, in contrast to the Newtonian dynamics and the isotropic character of its space. The external moving cause is able to induce the physical irreversible process towards a new stability. Thus the educed form can be defined as the intrinsic limit (act, entelécheia) and the irreversibility of the physical process is strictly linked with the role of the heat (Basti 2002, 440-446). In other words, Aristotle understood very well that the evolution of most of the natural processes cannot be univocally 
predict through mere knowledge of the initial conditions. The knowledge of the material cause (the position of the elements) and the moving cause (the forces) is not sufficient in order to predict the final state, as it was considered in the Newtonian-Laplace approach based on the apodictic-deductive method (in contrast to the mentioned hypothetical-deductive Aristotelian method). A sufficient knowledge would only come from the method of investigating the real objects:

Since 'nature' has two senses, the form and the matter, we must investigate its objects [...] That is, such things are neither independent of matter nor can be defined in terms of matter only. [...] Again, 'that for the sake of which', or the end, belongs to the same department of knowledge as the means. But the nature is the end or 'that for the sake of which'. For if a thing undergoes a continuous change and there is a stage which is last, this stage is the end or 'that for the sake of which'. (Aristotle, Physics, II, 2)

The form is the stage, the end of the continuous change, the "that for the sake of which". This means that for Aristotle the formal component does not only mean the stable, no-predicted state of a dynamic process, but also the capacity (medium) of the state to achieve the stable states by using different paths. It would be a big misunderstanding to interpret the identity of Aristotelian "physical form" only in geometric, extensional terms. On the other hand, what in geometric terms does not make sense, is totally justified in the semantic-intentional. Basti $(2005,181)$ gives the example of putting food on a plate. If we are in front of the buffet and we are moving our hand, the circumscription of our action is defined - the plate and the buffet - but the trajectories marked by the movement of the hand are casually and geometrically not identical. On the other hand this chaotic dynamic of the hand from the semantic point of view is formally identical. On this point it is evident that the Aristotelian concept of the form can contribute to the contemporary discussion about living beings as the biological and chemical dissipative systems characterized by the self-organization and self-adjustment. The Aristotelian idea of the form corresponds to the situation described by chaos theory, the problem of 
chaos systems which follow different and unpredictable paths and generate a new order - the information. The similarity of the material form to the mentioned chaotic attractors and the dissipative structures (paragraph 1.3.) is clear. As a consequence, the classical theories of information in relation to entropy cannot give a sufficient explanation of the complexity of biological and also cognitive processes.

\subsection{The distinction between living and inanimate matter}

The second fundamental point of Aristotelian ontology considers the distinction between living matter and inanimate matter. In living matter one can specify the difference between a formal component and aims. In living matter aims are in some way preexisting to the physical processes, because through the latter are achieved. Some of the aims can be genetically predetermined, although the path that the organism will choose for its development depends upon a huge amount of factors that are irreducible to the genotype. As a consequence the achievement of the phenotype cannot be deterministically described. In the case of the human being, intentionality allows man to choose in conscious way other aims different from those biologically determined. This human ability give us the basis for the reflection about human purposes and human freedom (Basti 2013). On this point it is worth mentioning the Aristotelian-Thomistic idea of the sensory stimulus (Basti 2012-2, 553-570). As it was mentioned earlier (paragraph 1.3.) the classical approach attempts search to find not only psycho-logical base for the human intentionality but most of all searches after the psycho-physical. In this context is significant remember the explanation of Thomas Aquinas:

Now, immutation is of two kinds, one natural, the other spiritual. Natural immutation takes place by the form of the immuter being received according to its natural existence, into the thing immuted, as heat is received into the thing heated. Whereas spiritual immutation takes place by the form of the immuter being received, according to a spiritual mode of existence, into the thing immuted, as the form of color is received into the pupil which does not thereby become colored. Now, for the operation of the senses, a spiritual immutation is 
required, whereby an intention of the sensible form is effected in the sensible organ. Otherwise, if a natural immutation alone sufficed for the sense's action, all natural bodies would feel when they undergo alteration. But in some senses we find spiritual immutation only, as in "sight" while in others we find not only spiritual but also a natural immutation [...] (Summa Theologiae, I, 78, 3).

Aquinas's concept of immutation explains how the sensory stimulus which has a double component - material (energetic input) related to the sensory organ and spiritual (input informational) related to the sensitive faculty. In other words, immutatio spiritualis and immutatio materialis do not imply some hidden spiritual force but are rather the technical terms used to describe the process of the human cognition. On the one hand, they refer to the idea inherited from Aristotelian physics of the so called diaphaneitas. These were physical, transparent bodies (e.g. water, air) that were able to transfer different information about physical properties of real objects. In the contrast to the non-diaphanous objects (that could be realized, determined only by one form), the diaphanous bodies could virtually transfer (e.g. to the human eye) different information regarding the perceived object. And because the human eye is full of water, it can receive virtually the forms of the perceived objects. On the other hand, the idea of immutatio spiritualis is related to Aquinas's explanation of the corporeal spirits which can be compared to the nervous stimulus distributed in the nerves, the brain, the organs and the muscles. They are the medium between the human mind and the body in order to perform intentional acts. But the corporal spirits are not considered by Thomas as the literal medium (instrument) between the soul and the body. They are rather, like in Aristotle, the formal dispositions (dispositio) of the body and its faculties. This means that in a Thomistic interpretation, the corporeal spirits' dynamics effect an upward (from the organs, nerves to the brain) and downward (from the brain to different corporeal parts) causation. This double casual direction is under the influence of double causality: psychological and metaphysical. The first causality consists in the relation between the intellectual and sensitive faculties. The second one consists in the relation between the soul and the body. But 
both of these causalities are grounded on the aforementioned dispositional causality: upward (passive) and downward (active). Thus, the senses which are passively modified (upward), then on the basis of the combined sense they are able to effect spiritual immutation through the corporeal spirits (downward). Hence Thomas defined the form that is induced by immutatio spiritualis as "an intention of the sensible form effected in the sensible organ". In other words, this form is the intentional form, because it is the result of the intentional act. This means that the living body is capable of self-organization (imminent actions) on three different levels - vegetative, sensorimotor and intellectual (Aquinas, S.Th. I, 18, 3; Basti 1991, 186-188, 202-206; 2008, 214-239). This theory of perception has contemporary correspondence in the studies of modern neuroscience, in that the behavior of neural networks can be modeled in the categories of chaos theory (stochastic behavior). The complex cerebral dynamics ("the cacophony" of the cerebral waves), the apparently chaotic activity of the brain, is transmitting precise signals at the cerebral macroscopic level. The Freeman's and Rizzolatti's discoveries of the neural substratum of the intentional act constitute a solid base for the neurophysiological correlate (but not reductionist) of the human intentional act. Already in the Artificial Intelligence program of the 1960's focus was placed upon the idea of a distinction between the formal and material components of the neurophysiological event. However, the functionalist approach in neuroscience was insufficient to explain that distinction. Primarily because functionalism did not consider the complexity of cerebral dynamics, which are chaotic, able to not only calculate, but to generate information without violating the principle of the conservation of energy. The shift of paradigm - from the representative paradigm of Artificial Intelligence to the intentional one of Computational Intelligence - demonstrates clearly that the human person is "the energetically and informational opened system” (Basti 2012-2, 568-570).

To sum up, the Aristotelian ontology can offer the mind-body problem an adequate solution. Firstly, according to Aristotle, the form never acts upon matter. On the one hand, the distinction between essence and existence and, on the other, the distinction between the formal and agent component of 
physical causality, allows us to study natural processes without violating the principle of the conservation of energy, as well as being able to consider the structural/informational growth. Secondly, the living body is characterized by its capacity to self-organization. Not only does the soul affect the body, but the body affects itself (immanent action). The body through its special parts (organs) is executing, on the different levels, the active control of its modification and behavior. Thirdly, the Aristotelian-Thomistic ontology can offer an attractive possibility to explicate philosophical problems in rigorous philosophical language. Especially, it would be possible to use the method of formal ontology. Generally, the huge potential of the dual approach is contained in a vision of reality totally different from the platonic and monistic interpretations. The fusion between the Platonism and monism resulted in the story of human thought, the strong conviction that the physical laws can be interpreted as the ideal, perfect, infinitely precise, immutable, unchangeable and everlasting mathematical laws that transcend the universe (P. Davies 2010, 71, 73). Thomas Aquinas approach, of course strictly immersed in Christian theological vision, together with ideas inherited from Aristotle, provides a causal explanation of reality, where not The Mind of God (ideas, ideal laws) but the First Cause (transcend and immanent) of the world gives an explanation of reality. Thus the numbers, laws, the forms exist in physical reality (are immanent to it) and only a study of reality, not of the pure forms, can give adequate answers for the eternal questions of the humanity (Basti 2012, 70-71).

\section{Conclusion}

As was shown, the progress of cognitive science is impressive. However, the current development can be interpreted as the change of scientific paradigm. From Galilean times the modern apodictic-mathematical method of science dominated human thought and prepared the conceptual background for many reductionist, fragmentary philosophical visions of reality. The Galilean paradigm of science was based on the assumption that the mathematico-logical hypothesis precedes observations. In other words, if we interrogate nature 
in mathematical language, it will respond. Furthermore, its basic assumption claims that empirical observation is the act of measuring. Observation is conducted on the basis of the theory's principles and the observation plays the role of verifying the truth of theory's hypothesis. As a consequence, the paradigm of modern science could be characterized as the representative, where the theories are based on extensional logics. But as has been shown, it is clear that the contemporary progress of cognitive science moves from representative, functionalism to the intentional approach - Computational Intelligence, the soft-computing (Basti 2009, 210-212).

This article is the attempt to describe this shift, including the intersection of different disciplines: physics, biology, logic, cognitive science, philosophy. Obviously it would exceed the scope of this article to explain in detail this ongoing shift in all these disciplines. But this article has shown from where this shift occurred and shown in which direction the change is going. The ordering of dissipative structures in non-equilibrium thermodynamics, the good theoretical framework of QFT, the study of chaotic systems, the cosmological and the neural interpretation of information, the use of modal logics and finally the Aristotelian-Thomistic theory of perception and ontology - all these elements need a separated, systematic explication but even in this text it has been shown that they undoubtedly encourage lively dialogue between philosophy and the contemporary sciences. They can offer the link between the macroscopic and microscopic phenomena, which is important for the study of the complex cerebral activity and for the examination of the emergence the ordered structures from the microscopic level, at mesoscopic and macroscopic ones. Thus the redefinition of the mind-body problem to the person-body is not only wishful thinking but has a solid foundation. The shift, as we are seeing, has its origin in the focus on man's place in the whole puzzle of the universe. In some way, the area of human inquiry was limited in the past from the "macro universe" to the "micro universe". But what is really fascinating is that humanity goes towards a real revolution. The real revolution has profound significance because it expresses the depth of the change within thinking. The real revolution means moving into the direction of unification and not isolation, which closes 
and produces ideologies. Talking about the person in neuroscience is a real revolution. We are moving towards the unification that does not reduce one element to another but reveals the richness of life.

\section{Bibliography}

Aristotele. 2015. L’anima. Edited and translated by G. Movia. Milano: Bompiani. Aristotle, Physics. R.P. Hardie and R.K. Gaye (trans.), University of Adelaide, (https:// ebooks.adelaide.edu.au/a/aristotle/physics/).

Basti, Gianfranco 1991. La relazione mente-corpo nella filosofia e nella scienza. Roma. Basti, Gianfranco \& Perrone, Antonio L. 1995. "Chaotic neural nets, computability, undecidability. An outlook of computational dynamics." International Journal of Intelligent Systems 10 (1995): 41-69.

Basti, Gianfranco \& Perrone, Antonio L. 2001. "Intentionality and Foundations of Logic: a New Approach to Neurocomputation" in What should be computed to understand and model brain function? From Robotics, Soft Computing, Biology and Neuroscience to Cognitive Philosophy, T. Kitamura (ed.), 239-288. Singapore-New York: World Publishing.

Basti, Gianfranco \& Perrone, Antonio L. 2002. "Neural nets and the puzzle of intentionality" in Neural Nets. WIRN Vietri-01. Proceedings of 12th Italian Workshop on Neural Nets, Vietrisul Mare, Salerno, Italy, 17-19 May 2001, R. Tagliaferri \& M. Marinaro (eds.), Berlin, London: Springer.

Basti, Gianfranco 2002. Filosofia della Natura e della Scienza. Vol. I: I Fondamenti. Roma: Lateran University Press.

Basti, Gianfranco 2005. "Il problema mente-corpo e la questione dell'intenzionalità" in L. Lenzi (ed.), 161-199. Neurofisiologia e teoria della mente. Vita e Pensiero: Milano.

Basti, Gianfranco 2007. "Ontologia formale: per una metafisica post-moderna” in A. Strumia (ed.) Il problema dei fondamenti. Da Aristotele, a Tommaso d'Aquino, all'ontologia formale. Siena: Cantagalli.

Basti, Gianfranco 2008. Filosofia dell'uomo. Roma.

Basti, Gianfranco 2009. "Logica della scoperta e paradigma intenzionale nelle scienze cognitive" in Quale scienza per la psicoterapia? Atti del III Congresso nazionale della SEPI (Society for the Exploration of Psychotherapy Integration). T. Carere-Comes (ed.), 183-216. Florence Art Edition. Firenze.

Basti, Gianfranco 2012. "Dualità, epigenesi, intenzionalità: dal mente-corpo al persona corpo.” Divus Thomas 115: 29-89. 
Basti, Gianfranco 2012-2. “Dal mente-corpo al persona-corpo: il paradigma intenzionale delle scienze cognitive” in E la coscienza? Fenomenologia, psico-patologia e neuroscienze, A. Ales-Bello, P. Manganaro (eds.), 523-634. G. Laterza, Bari.

Basti, Gianfranco 2013. "Persona, intersoggettività, realtà: i tre pilastri della relazione di cura" in Atti di Convegno Psicoterapia e Counseling: Comunanze e differenze, T. Carere-Comes, C. Montanari (eds.), 59-107. ASPIC Edizioni scientifiche. Roma. Basti, Gianfranco 2014. “Neuroetica e antropologia.” Camillianum XIV (41): 221-268. Basti, Gianfranco 2015. "Ontologia formale: uno strumento per il dialogo interculturale e interdisciplinare” in Ontologia formale, G. Basti, Sh. Mobeen (eds.), 13-137. Roma.

Basti, Gianfranco 2016. "QFT: An evolutionary interpretation of nature from cosmology to Neuroscience”. Accessed February 20, 2016. www.irafs.org/courses/ materials/qft_lecture_note.pdf

Bunge, Mario 1980. The Mind-Body Problem. Oxford.

Clark, Andy 2013. "Whatever next? Predictive brains, situated agents and the future of cognitive science." Behavioral and Brain Sciences 36: 181-204.

Cortez, Marc 2010. Theological anthropology: A Guide for the Perplexed. London-New York: T\&t Clark - Bloomsbury.

Cocchiarella, Nino B. 2007. Formal Ontology and Conceptual Realism. Berlin-New York. Damasio, Antonio R. 1994. Descartes' error. Emotion, reason and the human brain. Putnam's Sons. New York.

Damasio, Antonio R. 2010. Self comes to mind: constructing the conscious brain. Heinemann. London.

Davies, Paul 2010. "Universe from bit" in Information and the nature of reality. From physics to metaphysics, P. Davies, N.H. Gregersen (ed.), 65-91. Cambridge UP.

Donnellan, Keith S. 1966. "Reference and definite descriptions.” Philosophical Review 75: 281-304.

Fodor, Jerry A. 1980. The language of thought. Cambridge MA: Harvard UP.

Fodor, Jerry A. 2001. The Mind Doesn't Work That Way. The Scope and Limits of Computational Psychology. Cambridge MA: MIT Press.

Fodor, Jerry A. 2008. LOT2: The Language of Thought Revisited. Oxford, New York: Oxford UP.

Freeman, Walter J. 2001. How Brains Make Up Their Minds. Columbia University Press: New York.

Freeman, Walter J., Vitiello, Giuseppe 2006. “Nonlinear brain dynamics as macroscopic manifestation of underlying many-body field dynamics”. Physics of Life Reviews, 3 (2): 93-118. 
Freeman, Walter J., Vitiello, Giuseppe 2008. “Dissipation and spontaneous symmetry breaking in brain dynamics”. Journal of Physics A: Mathematical and Theoretical, 41 (30), 304042.

Kaplan, David 1978. "Dthat.” In Syntax and semantics 9: pragmatics, P. Cole (ed.), 221-243. New York: Academic Press.

Koyré, Alexandre 1980. Introduzione a Platone. Vellecchi. Firenze.

Kripke, Saul 1980. Naming and necessity. Cambridge MA: Harvard University Press. Lewis, Clarence I. 1912. “Implication and the Algebra of Logic.” Mind 21: 522-531. Lewis, Clarence I., Langford C.H. 1932. Symbolic Logic. Century Compan, New York (reprint in $2^{\text {nd }}$ Edition, Dover Publications, New York 1959).

Maritain, Jacques 1974. Distinguere per unire. I gradi di sapere. Brescia.

McKay, Donald M. 1980. “The interdependence of mind and brain.” Neuroscience 5: 1389-1391.

Newton, Isaac 1704. Optice. Translation by S. Clarke. Losanna-Ginevra.

Perrone, Antonio L. 1995. “A formal Scheme to Avoid Undecidable Problems. Applications to Chaotic Dynamics Characterization and Parallel Computation” in Lecture Notes in Computer Science, n. 888, 9-52. Berlin-Heidelbreg: Springer.

Perrone, Antonio L., Basti, G., Messi, R., Paoluzi, L., \& Picozza, P. 1995. “Principles of computational dynamics: applications to parallel and neural computations" in Applications of Artificial Neural Networks. SPIE Proceeding Series, 2492, S.K. Rogers \& D.W. Ruck (eds.), 368-372. Bellingham.

Popper, Karl R., Eccles, J.C. 1977. The Self and its Brain. Berlin-New York.

Penrose, Roger 1994. Shadows of the Mind. A Search for the Missing Science of Consciousness. Oxford UP.

Putnam, Hilary 1960. “Minds and Machines” in Dimension of mind, S. Hook (ed.). New York: Collier.

Putnam, Hilary 1975. Philosophical Papers II: mind, language and reality. Cambridge MA: MIT Press.

Putnam, Hilary 1988. Representation and reality. Cambridge MA: MIT Press.

Ryle, Gilbert 1951. The concept of mind. London.

Quine, Willard V. 1987. Quidditties. An intermittently philosophical dictionary. Cambridge MA: Harvard UP.

Rizzolatti, Giacomo, Sinigaglia, Corrado 2006. So quel che fai. Il cerevello che agisce e i neuroni specchio. Milano: Raffaello Cortina.

Salmon, Natan 2005. Reference and essence. New York: Prometeus Book.

Searle, John R. 1980. "Mind, brains and programs. A debate on artificial intelligence.” The Behavioral and Brain Science 3: 128-135. 
Searle, John R. 1983. Intentionality. An essay in the philosophy of mind. New York: Cambridge UP.

Searle, John R. 1994. The Rediscovery of the Mind. Massachusetts.

Searle, John R. 2004. Mind: A Brief Introduction. New York: Oxford University Press. Searle, John R. 2007. Freedom and neurobiology. Reflections on free will, language and political power. New York: Columbia University Press.

Thomas Aquinas, 1947. The Summa Theologica. Benziger Bros. edition. Translatedby Fathers of the English Dominican Province (http://dhspriory.org/thomas/ summa/).

Wheeler, John A. 1990. "Information, physics, quantum: The search for links" in Complexity, entropy, and the physics of information, W.H. Zurek (ed.). AddisonWesley, Redwood City.

Wheeler, John A. 1992. "Recent thinking about the nature of the physical world: It from bit" in Annals of the New York Academy of Sciences 655, 349-364. New York.

Woźniak, Robert J. 2014. “Materialno-biologiczny wymiar obrazu Bożego w człowieku.” Scientia et fides 2 (2): 271-288. 